\title{
UNTREATED HYPOTHYREOIDISMUS CAN LEAD TO SERIOUS CONSEQUENCES IN ALL ORGAN SYSTEMS
}

\author{
OLIVERA BOŠKOVIĆ, DRAGANA PRAVILOVIĆ, TEODORA VUJOVIĆ
}

CLINICAL CENTER OF MONTENEGRO, DEPARTMENT OF ENDOCRINOLOGY

\section{OBJECTIVES}

\section{To present a patient with all manifestations of long-term unsubstituted hypothyroidism- from alopecia to myxedema and megacolon}

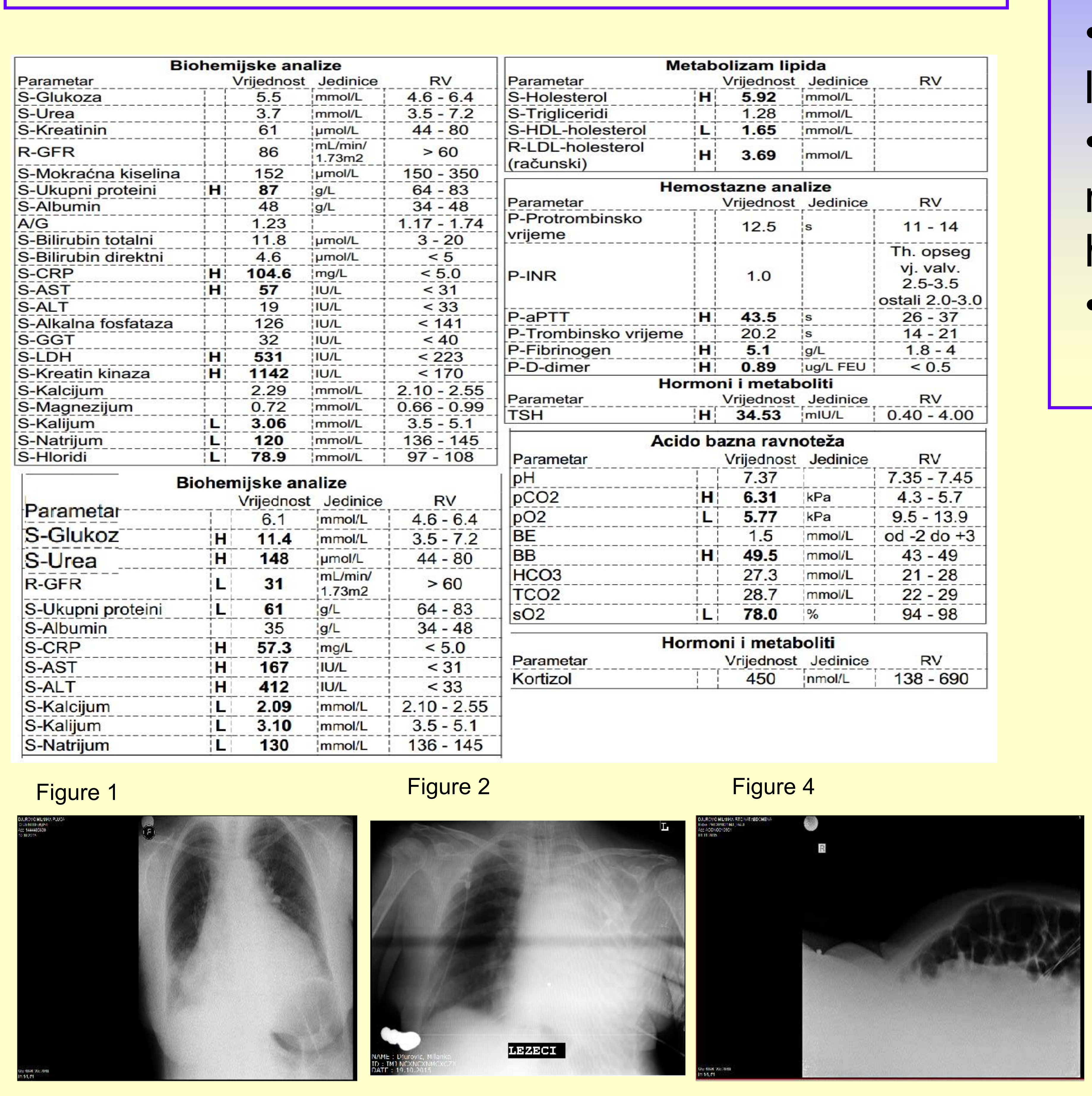

\section{METHODS}

Case:

- Sixty-one-old year women was admitted in ICU due to disturbance of consciousness, respiratory failure and electrolyte imbalance

- Sopor, expressed alopecia, dry, flaky, pail skin, generalized edema, lung stasis and pericardial friction (fig. 1, 3)

- A laboratory parameters pointed to the presence of normocytic normochromic anemia, hyponatremia, acidosis and hypoxia, and hormonal analyzes expressed in primary hypothyroidism

- In the immunological findings of elevated double-spiral DNA
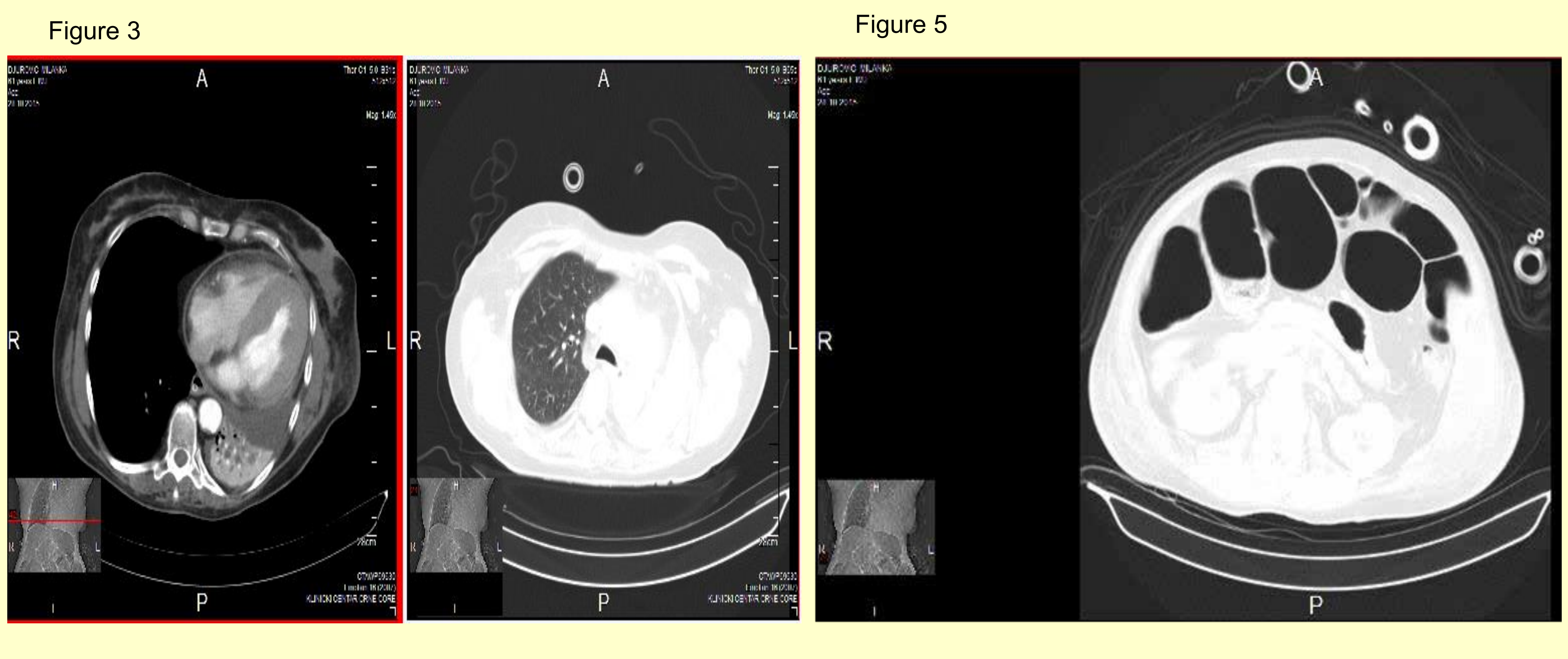

\section{RESULTS}

- To present a patient with all manifestations of long-term unsubstituted hypothyroidism-from alopecia to myxedema megacolon

- Visualization techniques proved the presence of pleural effusion and atelectasis of the left lung parenchyma ( fig.2), the presence of pericardial effusion (fig.1,3), a small amount of fluid in the abdomen, as well as expressed enlarged and filled with air both flexure and transverse section of the colon (Fig.4,5), and multiishaemical changes in white matter of the brain

- The patient was intubated, applied mechanical ventilation. We started substitution with levothyroxine, diuretics, corticosteroids and other sympthomatic therapy. She was treated with enema various times, repeatedly performed bronchoscopy treatment on 4 occasions, and tracheotomy was made

- The treatment led to an improvement in the sense of lowering the parameters of inflammation, improving the acid-base parameters and reexpansion of the lung parenchyma, and general condition of the patient was getting better

\section{CONCLUSIONS}

- The lack of treatment of hypothyroidism can lead to serious consequences in all organ systems

- Since the autoimmune process has never antigen completely sensitive, there is a possibility of affection more target tissues in autoimmune process and mutually overlapping signs and symptoms of various autoimmune diseases

- Elevated levels of double-spiral DNA in combination with the presence of and criteria indicate the presence of lupus disease

\section{References}

1. Hypothyroidism and megacolon;
Florani S, Reda G, Cesareo R,

Tomba G, Visentin PP; Minerva
Anestesiol. 1996 Jul-Aug;62(7-8):271-5

2. Myxedema Megacolon

Francis X. Solano Jr, MD

Randall C. Starling, MD; Gerald S. Levey,

MD; Arch Intern Med. 1985;145(2):231.

3. Kwaku MP, Burman KD. Myxedema

coma. J Intensive Care Med. 2007 Jul-
Aug. 22(4):224-31.

4. Klubo-Gwiezdzinska J, Wartofsky L.

Thyroid emergencies. Med Clin North Am.
2012 Mar. 96(2):385-403 